\title{
Les Songes drolatiques de Pantagruel, introduction de Michel Jeanneret
}

\section{Dario Cecchetti}

\section{Q OpenEdition}

1 Journals

\section{Edizione digitale}

URL: http://journals.openedition.org/studifrancesi/35872

DOI: 10.4000/studifrancesi.35872

ISSN: 2421-5856

\section{Editore}

Rosenberg \& Sellier

\section{Edizione cartacea}

Data di pubblicazione: 1 juillet 2005

Paginazione: 145-146

ISSN: 0039-2944

\section{Notizia bibliografica digitale}

Dario Cecchetti, «Les Songes drolatiques de Pantagruel, introduction de Michel Jeanneret», Studi Francesi [Online], 145 (XLIX | I) | 2005, online dal 30 novembre 2015, consultato il 19 avril 2021. URL: http://journals.openedition.org/studifrancesi/35872 ; DOI: https://doi.org/10.4000/studifrancesi. 35872

Questo documento è stato generato automaticamente il 19 avril 2021.

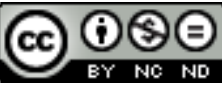

Studi Francesi è distribuita con Licenza Creative Commons Attribuzione - Non commerciale - Non opere derivate 4.0 Internazionale. 
Les Songes drolatiques de Pantagruel, introduction de Michel Jeanneret

Dario Cecchetti 


\section{NOTIZIA}

Les Songes drolatiques de Pantagruel, introduction de Michel Jeanneret, postface de Frédéric Elsig, Genève, Droz («Titre courant», 33), 2004, pp. 197.

1 Nel 1565 compare un misterioso libretto dal titolo Les Songes drolatiques de Pantagruel, où sont contenues plusieurs figures de l'inuention de maistre François Rabelais: \& derniere cuvre d'iceluy, pour la recreations des bons esprits (A Paris, Par Richard Breton, Rue S. Iaques, à l'Escreuisse d'argent. M. D. LXV.). La lettera Au lecteur attribuisce, come è già detto nel titolo, quest'opera a Rabelais, senza peraltro fornire precisazioni. Si tratta di un piccolo gioiello della gravure e della imprimerie cinquecentesca, che propone il tema del mostro, con immagini che si apparentano a iconografie illustri come quelle di Bosch e di Bruegel, e si susseguono senza legenda e senza che si possa ricostruire un ordine connesso al testo rabelaisiano. La ristampa moderna, bella e nitida, è accompagnata da una prefazione di uno storico della letteratura, Michel Jeanneret (pp. 7-47), e da una postfazione di uno storico dell'arte, Frédéric Elsig (pp. 175-196), che situano la silloge di incisioni nel contesto culturale, illustrando l'ambiente degli stampatori e decoratori parigini. Se a livello figurativo ritroviamo la tradizione delle drôleries, che risale al Medioevo e culmina, nel Rinascimento, nelle grandi invenzioni di Hieronymus Bosch, a livello di immaginario letterario - e di espressione concettuale attraverso il simbolo nell'universo mentale del Rinascimento ritroviamo, in posizione privilegiata, la rappresentazione del mostro. I due studiosi, pertanto, concludono le loro presentazioni del libretto, sottolineando che, se l'attribuzione a Rabelais è sicuramente falsa, le invenzioni di Rabelais si inseriscono a buon diritto nella stessa tradizione immaginifica cui appartengono le incisioni. 